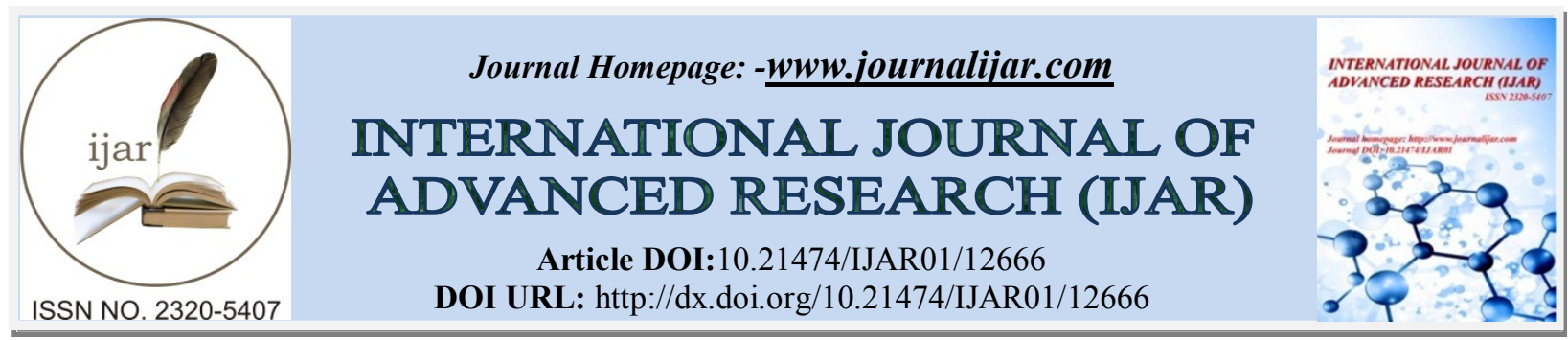

RESEARCH ARTICLE

\title{
HEREDITARY GINGIVAL FIBROMATOSIS: CLINICAL CASES AND LITERATURE REVIEW
}

\section{Mahad ${ }^{1}$, S. Haitami ${ }^{1}$, S. Adnane ${ }^{1}$, I. Chafi ${ }^{2}$ and I. Benyahya ${ }^{1}$}

1. Oral Surgery Department, Dental Consultation and Treatment Center,Faculty of Dentistry Casablanca Morocco.

2. Department of orthodontics, Dental Consultation and Treatment Center,Faculty of Dentistry Casablanca Morocco.

\section{Manuscript Info}

[.......................

Manuscript History

Received: 05 February 2021

Final Accepted: 10 March 2021

Published: April 2021

Key words:-

Hereditary Gingival Fibromatosis, Gingival Overgrowth, Clinical Features, Management

\section{Abstract}

Gingival fibromatosis (GF) is characterized by a slow and progressive proliferation that can affect the marginal and attached gingiva, or the inter-dental papillae. This condition can be localized or generalized, with varying degrees of severity.GF may develop in susceptible individuals as a side effect of systemic medications or as idiopathic gingival fibromatosis. It may also be related to hereditary factors and occurs as a non-syndromic hereditary gingival fibromatosis or as a part of a syndrome.Our aim is to describe trought four cases of hereditary gingival fibromatosis and a literature review the clinical features,etiopathogenesis, histopathological characteristics and treatment of this condition.

Copy Right, IJAR, 2021,. All rights reserved.

\section{Introduction:-}

Gingival fibromatosis (GF) represents a group of rare and heterogeneous diseases. It is characterized by a slow and progressive proliferation that can affect the marginal and attached gingiva, or the inter-dental papillae. This condition can be localized or generalized, with varying degrees of severity. In severe cases, excess tissue can cover the crowns and even delays teeth eruption, causing functional, aesthetic and periodontal problems. We discuss in this article clinical, histopathological and therapeutic aspects through four cases of Hereditary Gingival Fibromatosis. $(1,2)$

\section{First case report:}

A 21-year-old girl was admitted to the dental consultation and treatment center of Casablanca in Morocco following functional and aesthetic discomfort related to a significant increase in the gingival mucosa of the maxillae evolving since her childhood. Questioning noted the presence of similar lesions in family members, and no medical history that could be associated with gingival hyperplasia. Extra-oral examination revealed a convex profile with tight chin and prominent lips.Intra-oral examination showed generalized gingival hyperplasia covering completely the crowns of the molars, premolars and canines, and partially the incisors. The covering mucosa appeared normal and palpation revealed no pain but dense and fibrous consistency of the gingival tissue.(figure1-3) The radiological examination showed no abnormalities. (figure 4) The diagnosis of gingival fibromatosis has been suggested. The management required a resection with both conventional and electric scalpel over several sessions.(figure 5-8) Histological examination confirmed the clinical diagnosis with the presence of a reactive hyperplastic squamous membrane and a chorion with extensive fibrosis in thickened dense collagenic bands. Check-ups over several months showed a favorable evolution of the case with the establishment of orthodontic treatment.(figure 9-11) 


\section{Second and third case reports:}

An 18-year-old male patient was referred to the dental consultation and treatment center of Casablanca for gingival overgrowth evolving since childhood.Clinical examination revealed skeletal class 3 with generalized gingival hyperplasia.Dense and fibrous mucosa was covering the palate and partially the crowns of teeth resulting in the formation of pseudo pockets. Bite marks was noted on the mandibular mucosa covering the molars.(figure 12,13)The patient reported a similar condition in his family members including his father, his sister and two of his aunts, suggesting the diagnosis of hereditary gingival fibromatosis. Surgical resection was performed using the conventional scalpel. Microscopic examination confirmed the diagnosis and revealed a fibro-epithelialinflammatory hyperplasia with a squamous,acanthosic and keratotic mucosa, anda fibrous chorion dissociated by hyperplastic vascular structures with thickened walls and by a moderate inflammatory polymorphic infiltrate.Recurrences in the anterior sector were noted six years later,requiring reoperation. (figure 14,15)

The sister presented a similar increase in the gingival mucosa especially in the mandible. (figure 16-18)The radiological examination showed no abnormalities. The surgical resection was performed using electric scalpel and Diode laser. (figure 19-21)The evolution was favorable with no recurrence after five years. (figure 22-25)

\section{Fourth case:}

A 19-year-old young woman consulted at the Casablanca dental treatment center and was referred to our department for a bilateral palatal gum tumor that has been evolving for years ago.She reported that the problem had begun 4 years ago with slow progression.

Interrogation revealed no particular history; the patient did not report any history of metabolic disorder or any particular medication. She nevertheless reported discomfort with chewing, phonation and swallowing caused by the bilateral palatal gum mass, she also complains of difficulty brushing teeth.According to the patient, other members of the family are suffering from an increase in gum volume.

Extra -oral examination showed a respect of facial symmetry, brown teguments, and a skeletal class 3.Intra -oral examination revealed the presence of two bilateral palatal tumor masses, pedunculated, painless and firm on palpation, not bleeding on contact with a covering mucosa of normal appearance.It was extending from the molar region to the para-tuberosity region completely covering the dental surfaces of the posterior sectors. (figure 26)On panoramic radiological examination, we did not note any image of associated bone loss.In the light of these observations, a diagnosis of hereditary gingival fibromatosis was established.

The treatment consisted of surgical excision of the gingival hypertrophy using the electrosurgical unit on one side and the cold blade on the other, under a local anesthesia.(figure 27)The surgery was performed in two stages.

The patient returned one week later for a follow up appointment, the healing was good.She was seen one year later, no recurrence was observed.(figure28-30)

\section{Discussion:-}

GFmay develop in susceptible individuals as a side effect of systemic medications (anticonvulsant medication, immunosuppressant, calcium channel blockers) or as idiopathic gingival fibromatosis.It may also be related to hereditary factors and occurs as a non-syndromic hereditary gingival fibromatosis (HGF) or as a part of a syndrome such as Zimmermann-Laband, Rutherford, and Ramon syndromes.(1) (table 1)

The incidence of nonsyndromic hereditary gingival fibromatosis (HGF) has been described as one in 750000 individuals. Both genders are equally affected. The most frequent pattern of inheritance is autosomal dominant with high penetrance and variable expressivity. Linkage analysis has provided clues about the etiology of the disease, and showed several chromosomal regions that may contain mutations responsible for HGF. Five subtypes are described in the litterature, gingival fibromatosis Types 1-5 (GINGF1 to GINGF 5), corresponding to different candidate susceptibility loci. However, only two genes were clearly associated with the disease: son of sevenless-1 gene (SOS1; OMIM: 182530; GINGF1), identified by Hart et al in a Brazilian family, (4)and RE1-silencing transcription factor gene (REST; OMIM: 600571; GINGF5) described by Bayram et al(5)as the causal gene in three unrelated Turkish families. $(2,3)$ 
The gingival growth usually begins at the time of eruption of the permanent dentition but also may develop with the eruption of the deciduous dentition, and rarely is present at birth.(6)Also, the presence of teeth appears to be necessary for that the development of HGF occurs because the condition usually disappears or recedes with loss of teeth.(7)Furthermore, the gingival growth may worsen during adolescence, which agrees with the second case previously described, suggesting a possible influence of sex hormones on the pathogenesis of the condition.

The degree of severity of HGF is variable and can be classified as follows:

1. Grade 0: no gingival enlargement.

2. Grade I: enlargement confined to interdental papilla.

3. Grade II: enlargement involving papilla and marginal gingiva.

4. Grade III: enlargement covering three quarters or more of the crown. (8)

All the cases reported above had a severity level of class 2 to 3 .

The diagnosis of GF is made mainly on the basis of medical and family history, clinical and histopathological examination. If a genetic background is found, it is important to verify whether the lesion is an isolated entity or occurs as part of a syndrome and thus will require the use of laboratory tests. All of the cases described in this article have reported similar familial involvement. No patient presented with characteristic signs of any syndromic component, which led the diagnosis to hereditary gingival fibromatosis.

Clinically, HGF presents as an asymptomatic slow-growing generalized or localized gingival enlargement.The localized form typically affects the maxillary tuberosity and the labial gingiva of the lower molars.In the generalized form, the teeth are almost or completely covered. $(9,10)$ In some cases this condition can cause deformities in the palate contour, alteration of phonation, swallowing and chewing, diastemas, malpositioning of teeth, halitosis, prolonged retention of primary dentition, delayed eruption, inverted or open bite, prominent lips,open mouth posture, and mouth breathing.(11)Although the gingival enlargement does not directly affect the alveolar bone, the gingival overgrowth can lead to the formation of pseudo-pockets and predispose to bacterial accumulation inducing tissue inflammation and subsequently lead to the development of periodontal disease with bone loss. $(1,8)$

In our clinical case series, the gingival hyperplasia covered the teeth leading to dental malposition and retention as well as the formation of pseudo-pockets with accumulation of plaque in the second patient, which may explain the presence of inflammation. However, no periodontal disease or bone loss was noted.

Histopathologically, HGF usually involves moderate hyperplasia of a dense, hyperkeratotic epithelium with elongated rete ridges. Epithelial hyperplasia can also occur as a consequence of acanthosis. The connective tissue in HGF exhibits an accumulation of excess collagen, and elastic and oxytalan fibers; but has relatively few fibroblasts and blood vessels. Enlarged fibroblasts appear to alternate with thin and thick collagen fibrils. HGF does not usually involve inflammation, and local accumulation of inflammatory cells can be found only in cases where pseudo pocketing resulted in plaque accumulation.(12)

Periodontal examination, including X-ray and histopathology serve mainly to assess the type (local, diffuse, fibrous or inflammatory) and the severity of gingival involvement, including bone erosion, and allow the physician to choose the optimal treatment option. (2)

The treatment varies according to the degree of severity. When gingival enlargement is minimal, measures of oral hygiene, periodontal treatment, and patient orientation are recommended.In more severe cases, surgical intervention is necessary due to functional and aesthetic impairment.Treatment consists of surgical excision of excess gingival tissue, often in a series of gingivectomies, which should be complemented by effective oral hygiene instructions. There are various procedures available for removal of HGF including surgery, electrocautery, and use of laser.(8)Some authors describe internal or external bevel gingivectomy as the treatment of choice, A cold scalpel provides greater tactile sensitivity and is preferable to laser: since there is no certainty about where the different components of the periodontium are located, there is a risk of excessive destruction of the soft tissues, root tissue or even the bone through direct removal or secondary thermal effects. $(6,13)$ On the other hand, the use of the laser and the electric scalpel reduces the risk of bleeding and pain,allows having good visibility and results in better patient acceptance.(2)All the surgical techniques described above were used for our cases. Gingivectomy was necessary in 
the first case given the importance and severity of the lesion; however the use of electro-surgery made it possible to ensure, at the same time, hemostasis.

Recurrence rate in HGF is very high after surgery, so the patient should be followed for considerable period of time and may require repeated surgery. The appropriate time of removal of recurrent gingival enlargement varies. According to Emerson and al, the best time to intervene is when all the permanent teeth have erupted.(2)

We have noticed a favorable development as well as an improvement in the quality of life in our patients. Recurrences were noted in the second patient after six years of follow-up requiring reoperation at a few sites.

\section{Conclusion:-}

Gingival fibromatosis is a disease whose severity can vary from a simple gingival hypertrophy to partial or total coverage of the teeth leading to functional and aesthetic consequences. The role of the dentist is essential in the diagnosis and the management of this pathology thus making it possible to improve the quality of life of his patients.

\section{Acknowledgments:-}

Special thank for DrO.Nabih for his contribution in the first clinical case.
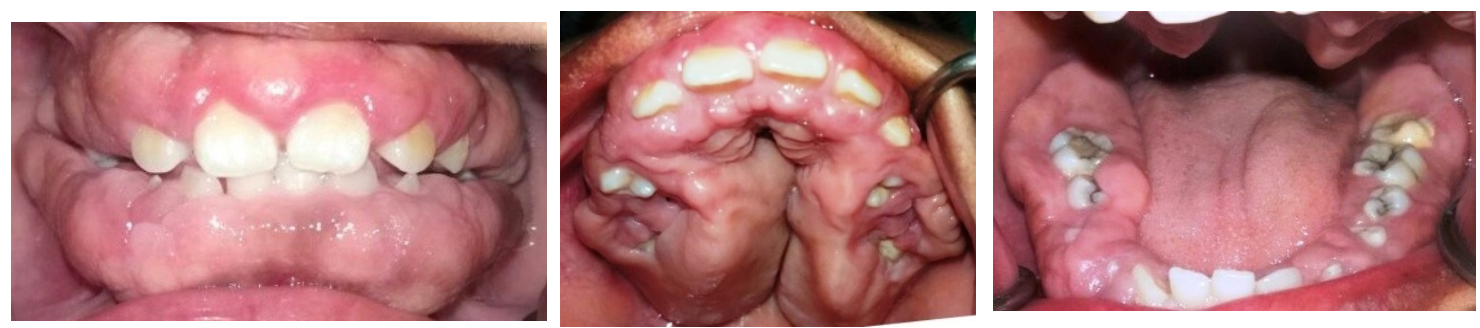

Figure 1-3:- Generalized fibrous gingival hyperplasia in the maxilla and mandible, on the vestibular, lingual and palatal surfaces completely covering the palatal vault and the crowns of the molars, premolars and canines, and partially the incisors.

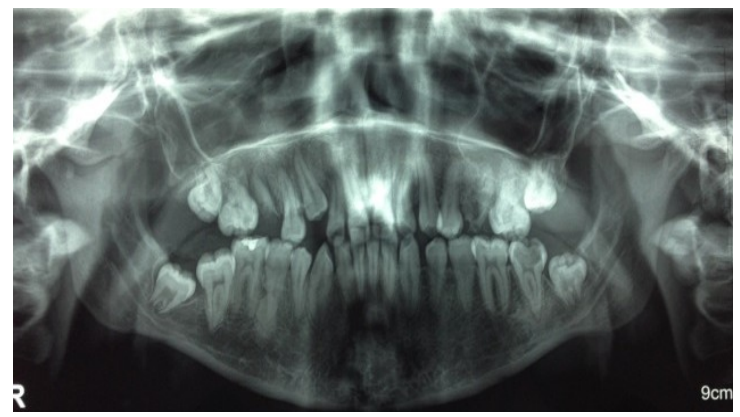

Figure 4:- Panoramic dental $\mathrm{x}$ ray showing dental malpostions and retainers, absence of maxillary canines.
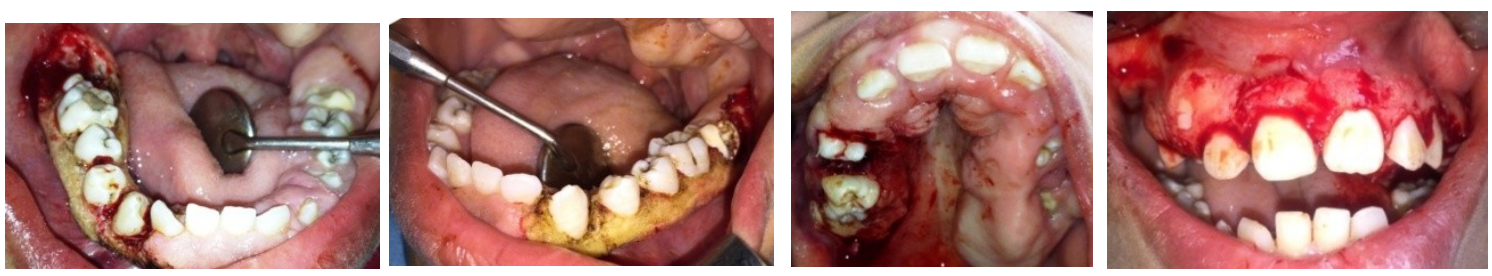

Figure 5-8:- A resection was performed with both conventional and electric scalpel by sector in several sessions. 

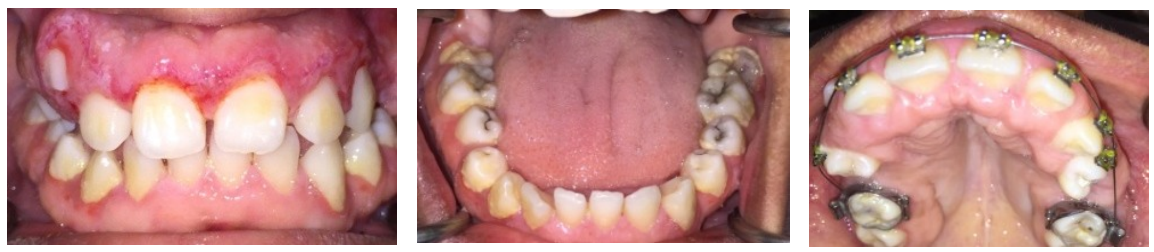

Figure 9- 11:- Control after 3, 6 and 12 months revealing a favorable evolution with no recurrence.

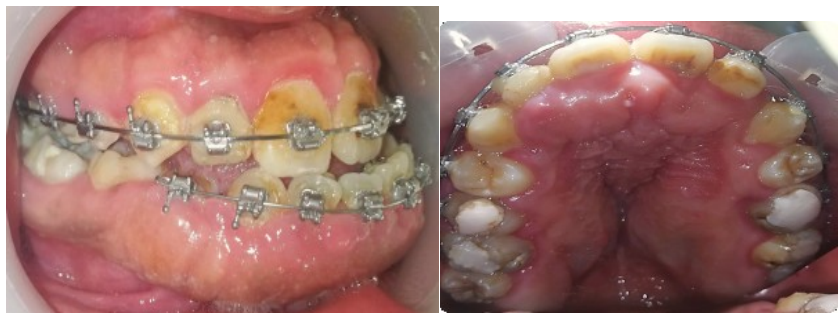

Figure 12,13:- Skeletal class 3 with generalized gingival hyperplasia.

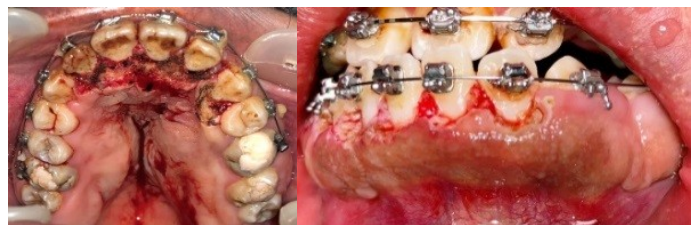

Figure 14,15:- Surgical resection performed using the electric scalpel in the maxilla and Diode laser in the mandible.

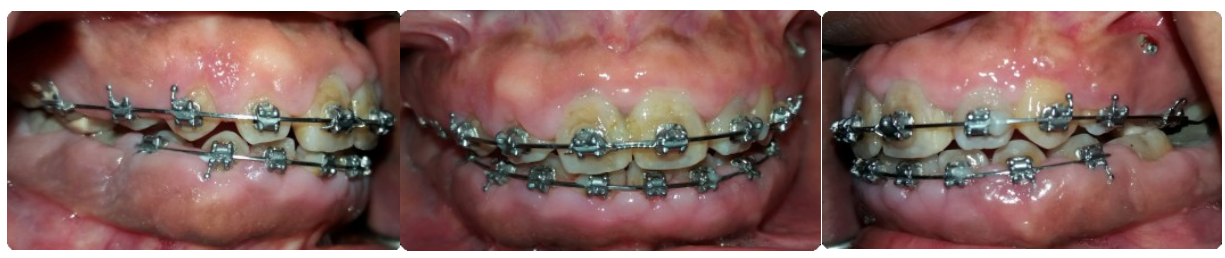

Figure 16-18:- The sister's case. Generalized gingival hyperplasia.

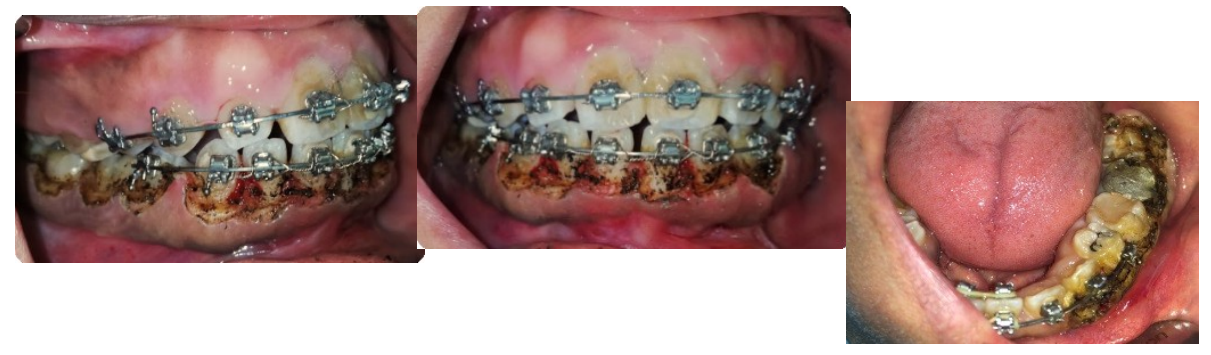

Figure 19-21:- Surgical resection using electric scalpel.

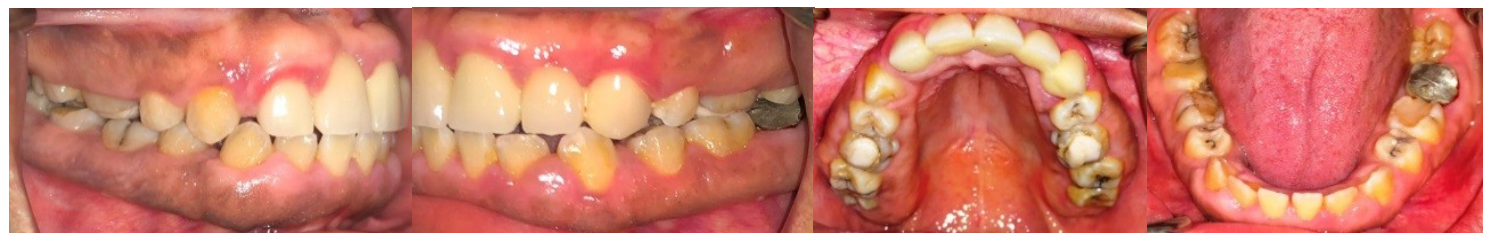

Figure 22-25:- clinical aspect five years later. No recurrences noticed. 


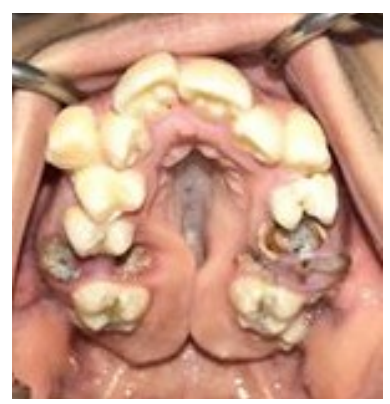

Figure 26:- Two bilateral palatal tumor masses pedunculated.

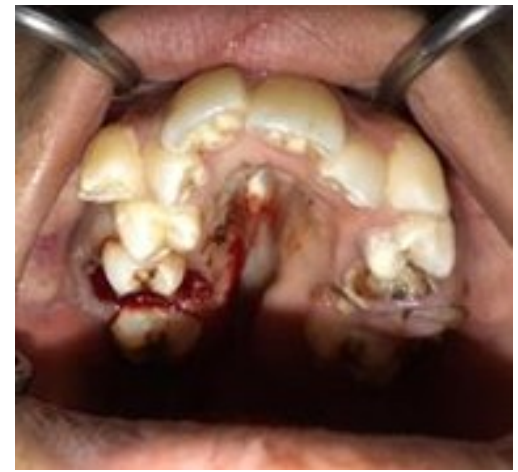

Figure 27:- Excision of the gingival hypertrophy using the electrosurgical unit and the cold blade.
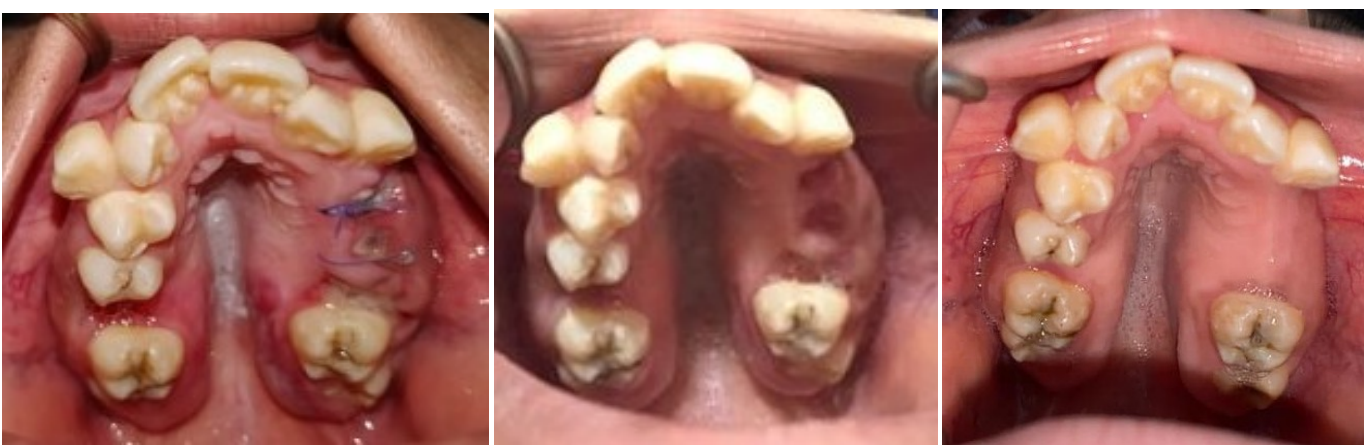

Figure 28-30:- Follow up after 1 week, 1 month and 1 year after the surgery: no recurrence was observed.

Table 1:- Syndromes Associated With HGF. (1).

\begin{tabular}{|l|l|l|}
\hline \multicolumn{1}{|c|}{ Syndrome } & \multicolumn{1}{c|}{ Inheritance } & \multicolumn{1}{c|}{$\begin{array}{c}\text { Features Apart From Gingival } \\
\text { Fibromatosis }\end{array}$} \\
\hline $\begin{array}{l}\text { Gingival fibromatosis } \\
\text { withhypertrichosis }\end{array}$ & Autosomal dominant & $\begin{array}{l}\text {-Hypertrichosis } \\
\text {-Mental retardation }\end{array}$ \\
\hline Zimmermann-Laband & Autosomal dominant & $\begin{array}{l}\text {-Ear and nose defects } \\
\text {-Dysplastic nails } \\
\text { - Hypoplastic terminal phalanges } \\
\text {-Joint hyperextensibility } \\
\text {-Hepatosplenomegaly }\end{array}$ \\
\hline $\begin{array}{l}\text { Murray-Puretic-Drescher (juvenile } \\
\text { hyaline fibromatosis) }\end{array}$ & Autosomalrecessive & $\begin{array}{l}\text {-Multiple hyaline fibromas } \\
\text {-Osteolysis of terminal phalanges } \\
\text {-Recurrent infections }\end{array}$ \\
& & $\begin{array}{l}\text {-Stunted growth } \\
\text {-Premature death }\end{array}$ \\
\hline Rutherfurd & & $\begin{array}{l}\text {-Corneal opacities } \\
\text {-Retarded tooth eruption }\end{array}$ \\
\hline
\end{tabular}




\begin{tabular}{|c|c|c|}
\hline $\begin{array}{l}\text { Gingival fibromatosis with } \\
\text { distinctive facies }\end{array}$ & Autosomal recessive & $\begin{array}{l}\text {-Macrocephaly } \\
\text {-Hypertelorism } \\
\text {-Bushy eyebrows with synophrys } \\
\text {-Downslanted palpebral fissures } \\
\text {-Flat nasal bridge } \\
\text {-Hypoplastic nares } \\
\text {-Cupid's bow mouth } \\
\text {-Highly arched palate }\end{array}$ \\
\hline Ramon & Autosomal recessive & $\begin{array}{l}\text {-Cherubism } \\
\text {-Hypertrichosis } \\
\text {-Mental deficiency } \\
\text {-Epilepsy } \\
\text {-Stunted growth } \\
\text {-Juvenile rheumatoid arthritis } \\
\text {-Ocular abnormalities }\end{array}$ \\
\hline Cross & Autosomalrecessive & $\begin{array}{l}\text {-Microphthalmia } \\
\text {-Mental retardation } \\
\text {-Athetosis } \\
\text {-Hypopigmentation }\end{array}$ \\
\hline Jones & Autosomal dominant & -Progressive deafness \\
\hline Prune-belly & Unclear & $\begin{array}{l}\text {-Absence of abdominal muscles } \\
\text {-Abnormalities of urinary tract } \\
\text {-Cryptorchidism } \\
\text {-Facial dimorphism }\end{array}$ \\
\hline
\end{tabular}

\section{References:-}

1. Coletta RD, Graner E. Hereditary gingival fibromatosis: a systematic review. J Periodontol. 2006 May;77(5):753-64. doi: 10.1902/jop.2006.050379.

2. Gawron K, Łazarz-Bartyzel K, Potempa J, Chomyszyn-Gajewska M. Gingival fibromatosis: clinical, molecular and therapeutic issues. Orphanet J Rare Dis. 2016 Jan 27;11:9. doi: 10.1186/s13023-016-0395-1.

3. Resende EP, Xavier MT, Matos S, Antunes AC, Silva HC. Nonsyndromic hereditary gingival fibromatosis: characterization of a family and review of genetic etiology. Spec Care Dentist. 2020;1-9. https://doi.org/10.1111/scd.12458.

4. Hart TC, Zhang Y, Gorry MC, et al. A mutation in the SOS1 gene causes hereditary gingival fibromatosis type 1. Am J Hum Genet. 2002;70:943-954.

5. Bayram Y, White JJ, Elcioglu N, et al. REST final-exon-truncating mutations cause hereditary gingival fibromatosis. Am J Hum Genet. 2017;101:149-156.

6. Almiñana-Pastor PJ, Buitrago-Vera PJ, Alpiste-Illueca FM, Catalá-Pizarro M. Hereditary gingival fibromatosis: characteristics and treatment approach. J ClinExp Dent. 2017;9(4):e599-602. http://dx.doi.org/10.4317/jced.53644.

7. Tandon S, Sharma M, Gandhi M, Vijay A. Nonsyndromic gingival fibromatosis: a rare case report. Int J ClinPediatr Dent. 2018;11(3):250-3. http://dx.doi.org/10.5005/jp-journals-10005-1521.

8. Cunha JLS, Ramos MACC, Regis DM, et al. Generalized hereditary gingival fibromatosis in a child: clinical, histopathological and therapeutic aspects. Autops Case Rep [Internet].2020 Jan.-Mar.;10(1):e2020140. https://doi. org/10.4322/acr.2020.140.

9. Lobo TM, Pol DG, Pol SD. Idiopathic gingival fibromatosis with asymmetrical presentation and electrosurgical management. J Indian SocPeriodontol. 2016;20(1):98-102. http://dx.doi.org/10.4103/0972-124X.170831.

10. Beaumont J, Chesterman J, Kellett M, Durey K. Gingival overgrowth: part 1: aetiology and clinical diagnosis. Br Dent J. 2017;222(2):85-91. http://dx.doi.org/10.1038/sj.bdj.2017.71.

11. Suassuna TM, Almeida AB, Landim FS, Medeiros MF, Perez DEC. Extensive idiopathic gingival fibromatosis: a case report. RevCirTraumatolBuco-Maxilo-Fac. 2016;16(4):40-44.

12. AkhilanandChaurasia. Hereditary gingival fibromatosis. Natl J Maxillofac Surg. 2014 Jan-Jun; 5(1): 4246. doi: 10.4103/0975-5950.140171.

13. Cohen RE, Ammons WF. Lasers in periodontics. Report of research, Science and Therapy Committee, American Academy of Periodontology (revised by LA Rossman) J Periodontol. 2002;73:1231-9. 